\title{
Site dependence of far-source ground motions during the Wenchuan earthquake*
}

\author{
Longjun $\mathrm{Xu}^{1, \star}$ Haiying $\mathrm{Yu}^{2} \quad{\text { Wenhai } \mathrm{Cao}^{3}}^{3}$ and Lili Xie $^{1}$ \\ ${ }^{1}$ Research Center of Civil Engineering Disasters and Prevention, Harbin Institute of Technology \\ at Weihai, Weihai 264209, China \\ ${ }^{2}$ Institute of Engineering Mechanics, China Earthquake Administration, Harbin 150080, China \\ ${ }^{3}$ Earthquake Administration of Weihai City, Weihai 264209, China
}

\begin{abstract}
This paper aimed to examine the site dependence and evaluate the methods for site analysis of far-source ground motions. This was achieved through the examination of frequency content estimated by different methods based on strong ground motions recorded at twelve far-source stations in Shandong province during the Wenchuan earthquake. The stations were located in sites with soil profiles ranging from code classes I to III. Approaches used included the Fourier amplitude spectrum (FAS), the earthquake response spectrum (ERS), the spectral ratio between the horizontal and the vertical components $(H / V)$, the spectral ratio between the spectra at the site and at a reference site (SRRS), and coda wave analysis (CWA). Results showed that major periods of these ground motions obtained by FAS, ERS and $H / V$ ratio methods were all evidently larger than site dominant periods; the periods were also different from each other and mainly reflected the frequency content of long period components. Prominent periods obtained by the SRRS approach neither illuminated the long period aspect nor efficiently determined site features of the motions. The CWA resulted in a period close to site period for stations with good quality recordings. The results obtained in this study will be useful for the evaluation of far-source effect in constructing seismic design spectra and in selecting methods for ground motion site analysis.
\end{abstract}

Key words: Wenchuan earthquake; far-source long period ground motion; predominant period; source effect; site condition CLC number: P315.9 Document code: A

\section{Introduction}

With increasing in number of large structures, such as high-rise buildings, oil storage tanks, suspension bridges, off-shore platforms, wind power structures, base-isolated and supplementary damped systems, far-source long-period (up from $3 \mathrm{~s}$ to $10 \mathrm{~s}$ or longer) earthquake effects have become increasingly important in seismic design (Yu, 2004; Li and Zhang, 2006; Fukuwa, 2008). However, long-period effects are seldom considered especially in code provisions worldwide. Present researches of long-period ground motions in China mainly focus on characteristics of response spectra in long period ranges (Xie et al, 1990; Li et al, 2006). Far-source ground motions, which are generated by Rayleigh and Love waves, consist primarily of longperiod component with longer durations than ordinary

\footnotetext{
* Received 24 February 2009; accepted in revised form 15 July 2009; published 10 October 2009.

- Corresponding author. e-mail: xulongjun80@163.com
}

earthquake motions. Such motion waves can cause ground disturbance to develop in a nearly harmonic manner over long intervals at large distances (200-2 000 $\mathrm{km}$ ) from the epicenter, and thus resonance in structures or seiches with corresponding natural frequencies of motion. The destructive impact of far-source ground motions have been identified in recent earthquakes, such as the 1985 Michoacan, the 1999 Jiji (Chi-Chi), the 2003 Tokachi-oki and the 2008 Wenchuan events (Beck and Hall, 1986; Celebi et al, 1987; Boore, 2001; Koketsu et al, 2005; Xu et al, 2009; Maeda and Sasatani, 2008).

To evaluate the earthquake resistance of large structures and systems, civil engineers need a reliable estimate of the frequency content of site-specific, far-source long period ground motion, hence, the nature of far-source ground motions and influence factors on the wave need to be thoroughly analyzed. This paper aims at the characteristics of the frequency content of far-source ground motions (with epicentral distance of more than $1000 \mathrm{~km}$ ) recorded in Shandong province during the great 2008 
Wenchuan earthquake. For this purpose, different approaches for evaluation on ground motion stations have been applied. Finally, we conclude that the frequency content of far-source ground motions are controlled mainly by source and path, while have poor correlativity with effect of local site conditions. Thus, usual methods for site evaluation cannot be applied to those types of motions. Though this work only based on limited station recordings of single earthquake event, it is expected that the study of the work will be useful to evaluate the far-source effect in constructing design spectra and in selecting methods for ground motion site analyzing.

\section{Far-source ground motion data}

On May 12, 2008, a catastrophic earthquake $\left(M_{\mathrm{S}} 8.0 ; 31.00^{\circ} \mathrm{N}, 103.40^{\circ} \mathrm{E}\right)$ struck Wenchuan, Sichuan province in China. During the earthquake, the National Strong Motion Observation Network System (NSMONS) obtained records from 420 stations in 19 provinces, municipalities and autonomous regions (Yu et al, 2009).
Many far-field recordings were obtained. There are seventeen stations in Shandong province, which recorded the earthquake information with duration varying from $60 \mathrm{~s}$ to about $1000 \mathrm{~s}$. To examine the influence of duration on frequency content, taking DTT station for example, the response spectra of the NS component for motions with different duration (700, 500, 300, 200, 150 and $100 \mathrm{~s}$, respectively) are computed and shown in Figure 1, and it is found that response spectra differ less for different motions when time lasts more than $200 \mathrm{~s}$, while the spectral values decrease evidently when time less than $200 \mathrm{~s}$. For this reason, ground motions from eleven stations were included in the study. The recording times from these stations are all longer than 200 s. To evaluate the frequency content of motion on rock site, $\mathrm{ZCH}$ station (the only station on rock site) is compiled in the data though its recording lasts only $60 \mathrm{~s}$. The totally 12 stations selected and ground motion information are listed in Table 1.

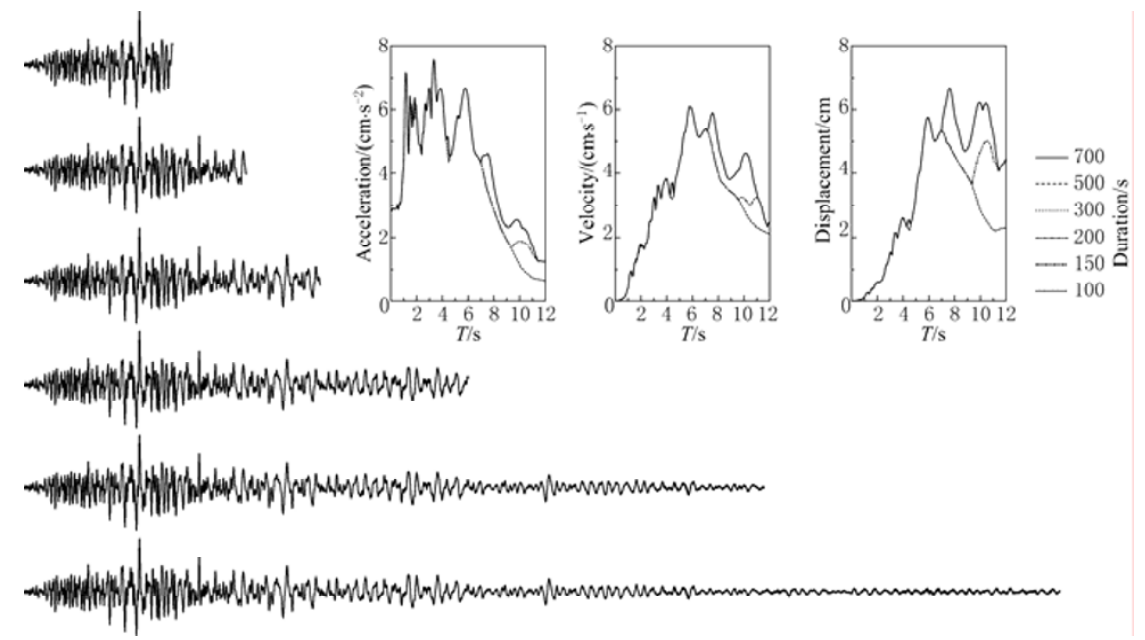

Figure 1 Influence of duration on recordings at DTT station.

Table 1 Station and ground motion information

\begin{tabular}{|c|c|c|c|c|c|c|c|c|c|c|c|}
\hline \multirow{2}{*}{ Station } & \multirow{2}{*}{ Code } & \multirow{2}{*}{$\begin{array}{l}\text { Lat. } \\
{ }^{\circ} \mathrm{N}\end{array}$} & \multirow{2}{*}{$\begin{array}{l}\text { Long. } \\
{ }^{\circ} \mathrm{E}\end{array}$} & \multirow{2}{*}{ Accelerometer } & \multirow{2}{*}{ Site } & \multirow{2}{*}{ Class } & \multirow{2}{*}{$\begin{array}{c}\text { Period } \\
/ \mathrm{s}\end{array}$} & \multirow{2}{*}{$\begin{array}{c}\text { Epicentral } \\
\text { distance/km }\end{array}$} & \multicolumn{3}{|c|}{$\mathrm{PGA} / \mathrm{cm} \cdot \mathrm{s}^{-2}$} \\
\hline & & & & & & & & & EW & NS & UD \\
\hline Dongming & DMT & 35.316 & 115.210 & ETNA/SLJ-100 & Soil & III & 0.35 & 1197 & 8.988 & 9.797 & 2.492 \\
\hline Juancheng & $\mathrm{JCH}$ & 35.595 & 115.491 & GDQT-2/SLJ-100 & Soil & III & 0.33 & 1232 & 3.513 & 4.781 & 1.912 \\
\hline Shenxian & SHX & 36.250 & 115.671 & ETNA/SLJ-100 & Soil & III & 0.32 & 1274 & 5.576 & 5.598 & 1.860 \\
\hline Linqing & LQT & 36.827 & 115.710 & ETNA/SLJ-100 & Soil & III & 0.34 & 1305 & 5.410 & 4.908 & 1.863 \\
\hline Zoucheng & $\mathrm{ZCH}$ & 35.386 & 117.019 & GDQT-2/SLJ-100 & Rock & I & 0.10 & 1355 & 0.572 & 1.893 & 0.924 \\
\hline Junan & JUN & 35.360 & 118.669 & ETNA/SLJ-100 & Hard soil & II & 0.10 & 1498 & 0.696 & 1.007 & 0.920 \\
\hline Binzhou & $\mathrm{BZH}$ & 37.373 & 117.951 & GDQT-2/SLJ-100 & Soil & & & 1510 & 2.463 & 2.623 & 0.968 \\
\hline Shanglin & SHL & 36.543 & 118.690 & ETNA/SLJ-100 & Soil & II & 0.23 & 1538 & 0.846 & 1.198 & 0.709 \\
\hline Daotian & DTT & 36.820 & 118.901 & ETNA/SLJ-100 & Soil & III & 0.32 & 1566 & 2.304 & 2.709 & 1.299 \\
\hline Haihua & HHT & 37.135 & 118.971 & ETNA/SLJ-100 & Soil & III & 0.39 & 1584 & 2.072 & 2.311 & 1.206 \\
\hline Liutuan & LTT & 36.943 & 119.391 & ETNA/SLJ-100 & Soil & III & 0.43 & 1611 & 4.155 & 4.227 & 2.106 \\
\hline Longkou & LKT & 37.638 & 120.501 & ETNA/SLJ-100 & Soil & II & 0.18 & 1731 & 1.008 & 1.434 & 0.936 \\
\hline
\end{tabular}


Each selected station consists of three components (EW, NS and UD). Ground motions are all recorded by high-quality digital accelerometers, and have been corrected and processed by Chinese Strong Motion Observation Network Center. To insure a reliable signal to noise ratio, we have processed these records by a limit filter bandwidth of $0.05 \mathrm{~Hz}$ to $25 \mathrm{~Hz}$ (Wang et al, 1998; $\mathrm{Yu}$ and $\mathrm{Hu}, 2001$ ). Based on station site data from the Earthquake Administration of Shandong Province, the 12 stations are located in sites with soil profiles ranging from classes I to III designed by China Building Code (CBC) for Seismic Design with site predominant periods of $0.1 \mathrm{~s}$ to $0.43 \mathrm{~s}$, respectively. All of the stations are located in the northeast direction within an angle of about $10^{\circ}$. A schematic position relation between the stations and epicenter of the earthquake has been illustrated in Figure 2.

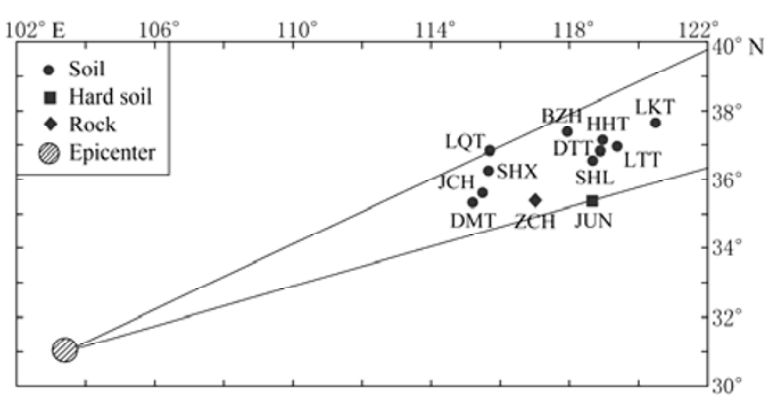

Figure 2 Schematic position relation of strong motion stations and the earthquake epicenter.

\section{Method analysis for prominent period}

\subsection{Fourier amplitude spectrum (FAS)}

Fourier amplitude spectrum of ground motion component could be obtained through fast Fourier transform. The Fourier amplitude spectrum with unit of velocity is a common tool in characterizing frequency content of ground motions; good results have been achieved to infer dominant frequencies from earthquake records of a site (Lermo and Chavez-Garcia, 1994). It should be noted that the interpretation of the prominent periods can be different for ground motions where the dominant period of the record may be effected by many factors.

\subsection{Earthquake response spectrum (ERS)}

For a given ground motion, the maximum deformation response, velocity response and total acceleration response of the system depend on the natural vibration period $T_{\mathrm{n}}$ of the system and its damping ratio $\zeta$. A plot of the peak response value of a quantity as a func- tion of the natural vibration period $T_{\mathrm{n}}$ (or circular frequency $\omega_{\mathrm{n}}$ ) is called the earthquake response spectrum (ERS) for that quantity (Chopra, 2007). Unlike the Fourier amplitude spectrum which presents information about frequent content of ground motion, the earthquake response spectrum presents the maximum response of a structure to a given movement, which can directly reflect the dominant period and amplification relations from it. However, the response spectral dominant period may not have direct relations to the site periods because many factors can significantly affect the spectrum shape.

\subsection{Horizontal to vertical spectral ratios ( $H / V$ )}

This method is proposed by Nakamura (2000) and in essence involves calculating the spectral ratio between the horizontal components and vertical component of the observed motion at the same site. The approach has been used primarily with microtremor recordings, but it can also be applied to earthquake recordings. The main advantage of the technique is that no bedrock site of reference is required for application. Despite the apparent appeal of Nakamura's method, the validity of its results and assumptions has not yet been established, especially in deep soft layers. The $H / V$ ratio presented in this paper is defined as

$$
\frac{H}{V}=\sqrt{\frac{H_{\mathrm{EW}}^{2}+H_{\mathrm{NS}}^{2}}{2 V^{2}}},
$$

where $H_{\mathrm{EW}}, H_{\mathrm{NS}}$ and $V$ are the two horizontal spectral value and vertical spectral value, respectively.

\subsection{Spectral ratios with respect to a reference site (SRRS)}

This method refers to as Kagami spectrum and sometimes as the Borcherdt method. Kagami et al (1982) used the approach to microtremors and Borcherdt (1970) applied it to ground motions. This method consists of calculating the ratio of the horizontal components of the Fourier spectral amplitudes of the motions recorded at a soil site and that of a nearby reference rock site. The spectral ratio $K_{\mathrm{SB}}$ is computed as:

$$
K_{\mathrm{SB}}=\frac{H_{\mathrm{S}}}{H_{\mathrm{B}}},
$$

where $H_{\mathrm{S}}$ is the horizontal component spectrum of the signal in soft soil, $H_{\mathrm{B}}$ the spectrum of the horizontal component in the rock site.

\subsection{Coda wave analysis (CWA)}

The seismograms of a local earthquake usually show some vibration long after the passage of body and surface waves. This portion of the seismograms to its 
tail end is called the coda waves. The coda wave is recognized as the back-scattering waves due to lateral inhomogeneity distributed throughout the Earth's crust and upper soil mantle (Aki and Chouet, 1975). The propagation paths of the coda wave depend only on the average regional properties of the soil layers above the bedrock, but are independent of any particular source-receiver location. The practicabilities of this method have been tested in some large earthquakes to infer resonance from earthquake records of a site (Ruiz and Saragoni, 2009). However, not all observed earthquake data are qualified to determine the site dominant period, because many of the induced response spectra are dominated by the source effect but not the site effect as it is expected (Chai et al, 2004).

\section{Analysis of the prominent periods for observed stations}

Figure 3 shows fast Fourier transform spectra (FFT) for ground motion components of each station; a summary of the corresponding spectral dominant periods is given in Table 2. It could be seen that most of the dominant periods range from $3 \mathrm{~s}$ to $7 \mathrm{~s}$, and the periods of
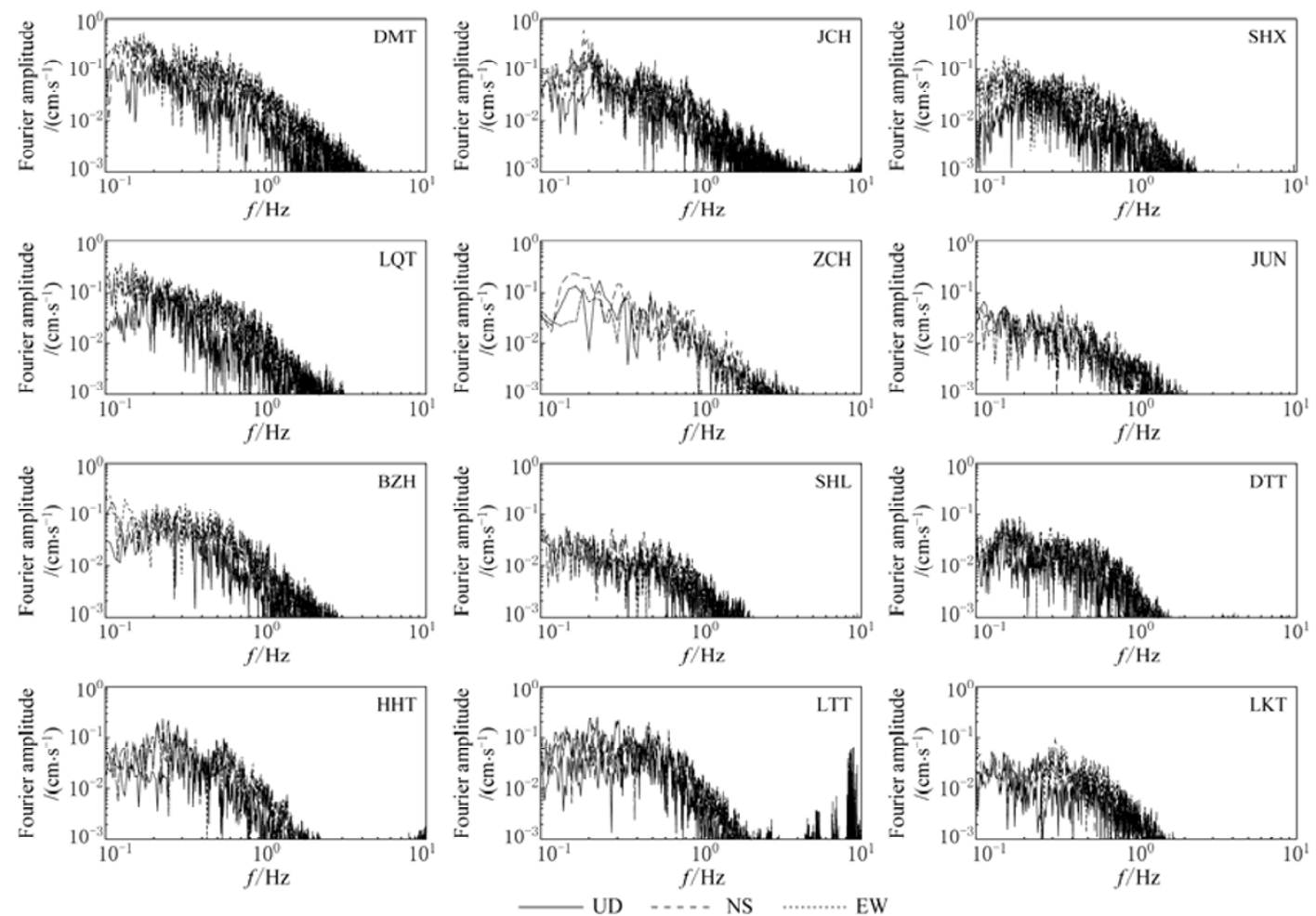

Figure 3 Fourier amplitude spectra for ground motions at different stations.

Table 2 A summary of the dominant periods for ground motion components at different stations

\begin{tabular}{|c|c|c|c|c|c|c|c|c|c|}
\hline \multirow{2}{*}{ Station code } & \multicolumn{3}{|c|}{ Dominant period with FFT/s } & \multicolumn{3}{|c|}{ Dominant period with ERS/s } & \multirow{2}{*}{$\begin{array}{c}\text { Dominant period } \\
\text { with } H / V \text { spectra /s }\end{array}$} & \multirow{2}{*}{$\begin{array}{l}\text { Dominant period } \\
\text { with SRRS /s }\end{array}$} & \multirow{2}{*}{$\begin{array}{l}\text { Dominant period } \\
\text { with CWA/s }\end{array}$} \\
\hline & EW & NS & UD & EW & NS & UD & & & \\
\hline DMT & 6.09 & 6.08 & 4.56 & 5.94 & 3.24 & 4.49 & 0.90 & & \\
\hline $\mathrm{JCH}$ & 4.77 & 5.39 & 4.41 & 5.14 & 4.80 & 3.32 & 5.25 & & \\
\hline SHX & 6.24 & 6.64 & 4.65 & 1.91 & 3.02 & 4.92 & 6.91 & & 0.23 \\
\hline LQT & 8.01 & 6.73 & 4.79 & 3.92 & 1.97 & 4.24 & 7.85 & & \\
\hline $\mathrm{ZCH}$ & 5.46 & 5.97 & 4.28 & 2.88 & 5.45 & 4.31 & 3.41 & & \\
\hline JUN & 6.66 & 2.93 & 8.90 & 1.85 & 1.99 & 2.85 & 2.09 & & \\
\hline BZH & 9.47 & 9.00 & 4.43 & 2.18 & 2.96 & 4.35 & 9.34 & & \\
\hline SHL & 9.50 & 3.59 & 6.92 & 1.77 & 3.08 & 2.01 & 3.32 & 1.24 & \\
\hline DTT & 5.33 & 5.91 & 6.83 & 1.79 & 3.34 & 3.22 & 6.09 & 1.19 & \\
\hline HНT & 4.03 & 4.40 & 3.66 & 3.49 & 1.81 & 2.26 & 4.49 & & \\
\hline LTT & 4.44 & 2.10 & 2.14 & 3.38 & 1.56 & 2.28 & 3.45 & 1.58 & \\
\hline LKT & 2.91 & 3.21 & 7.77 & 1.71 & 3.18 & 2.01 & 3.26 & & \\
\hline
\end{tabular}



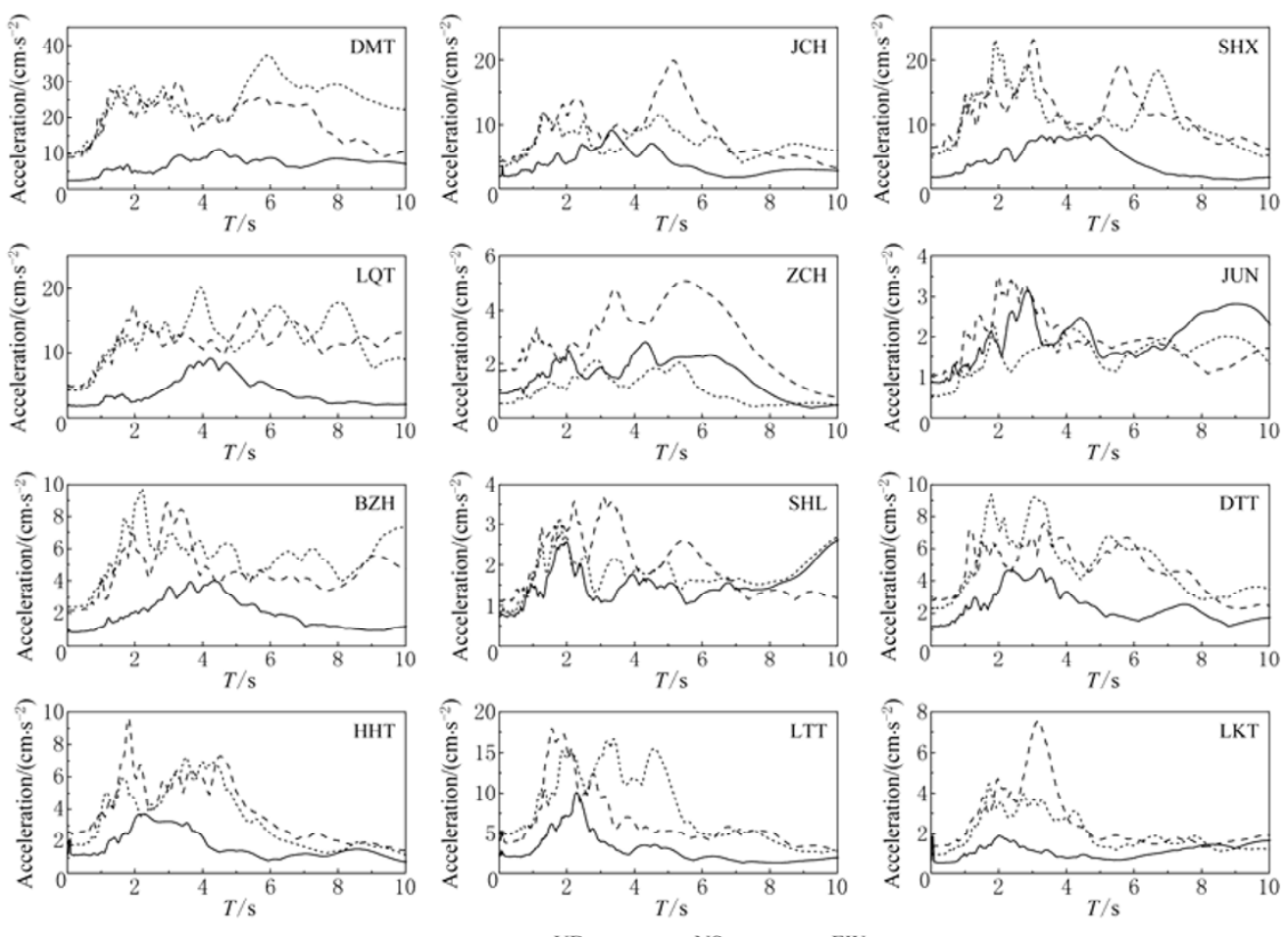

Figure 4 Response spectra for ground motions at different stations.
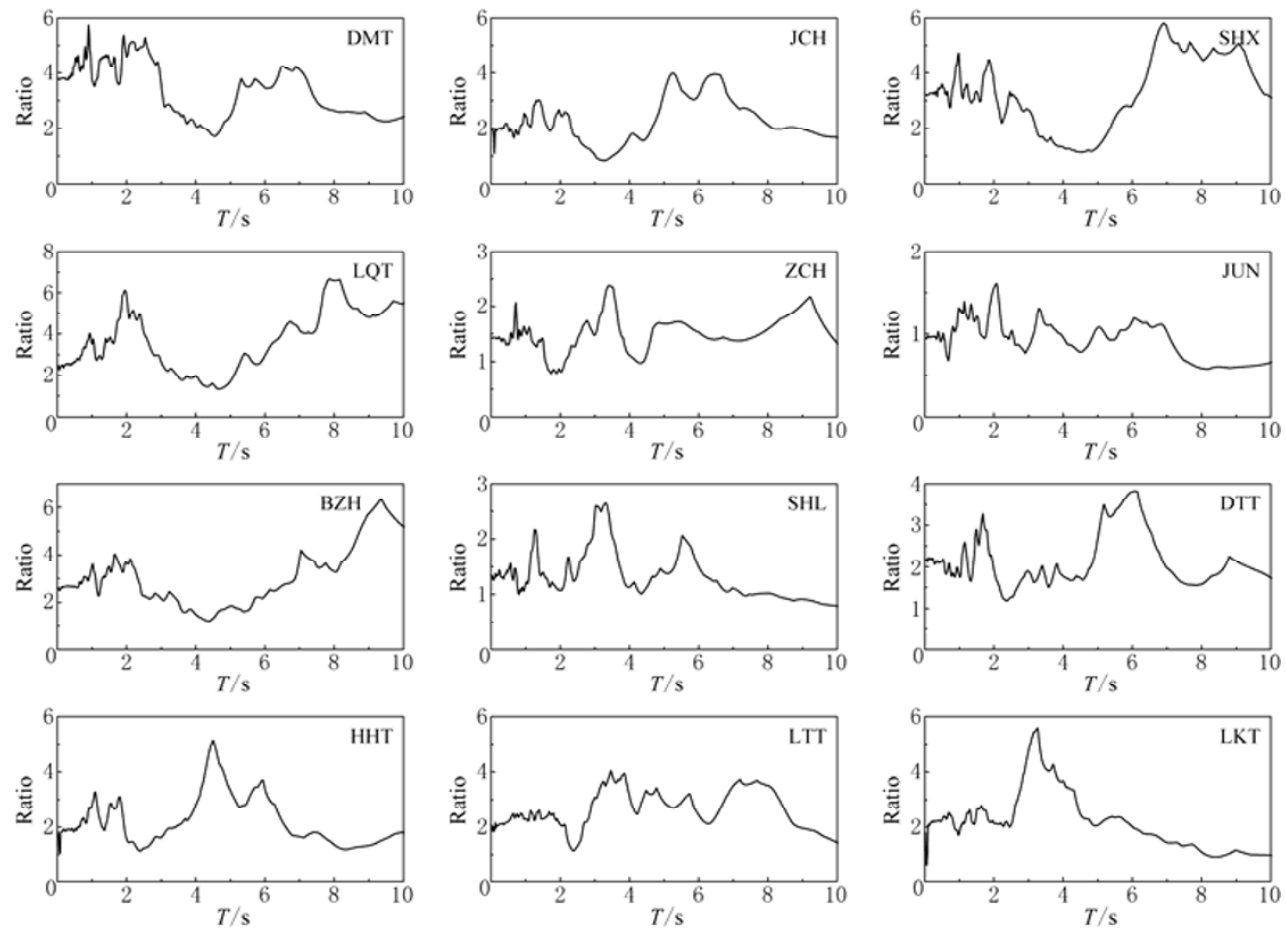

Figure $5 H / V$ curves for ground motions at different stations.

three components for one station are different from each other. It is noted that the prominent periods of the hori- zontal components for SHL and BZH stations are both larger than $9 \mathrm{~s}$, and period values for two stations of $\mathrm{ZCH}$ 
(rock) and JUN (hard soil) are also larger than 5 s. Evidently, dominant period could not reflect the influence of site conditions on far-source ground motions.

For the ground motion records, earthquake acceleration response spectra for 5\% damping have been calculated (Figure 4), the spectral dominant periods are listed in Table 2. Periods obtained from ground motions with response spectra and those by FAS are similar, which are far larger than site dominant periods. These observations are considered to be the effects of source and path rather than local site soil response for far-source seismic waves.

For further analysis, Nakamura spectra $(H / V)$ are computed according to equation (1). Figure 5 shows the $H / V$ spectra for each station and their prominent periods are given in Table 2. In this case, the dominant periods are approximately similar to that of the results obtained with the above two methods, and still could not emerge the influence of site conditions.

Ground motions at SHL, DTT and LTT stations are analyzed based on SRRS method, the nearby JUN station at hard soil site is selected as a reference site instead of $\mathrm{ZCH}$ station because its recordings last only $60 \mathrm{~s}$. Figure 6 presents the Kagami spectra (SRRS) of the three selected stations, dominant periods obtained are shown in Table 2. The results are evidently different from site dominant periods, but less than periods obtained by methods of FAS and ERS. Hence, the using of the SRRS approach could neither show the predominant frequency of the ground motion, nor reflect the impact of site soil.

The SHX station is selected for coda wave analysis because it has good quality recordings. Coda wave and the corresponding Fourier spectrum of the station NS component are plotted in Figure 7. It is clear that the dominant period is $0.23 \mathrm{~s}$, which is close to the site dominant period of $0.32 \mathrm{~s}$. It should be noted that the predominant frequency of local site is known before site characteristic is estimated by CWA method in the study. In fact, not all observed earthquake records are qualified to determine the site dominant period, site dynamic parameters could be efficiently determined only when more ground motions of a site are analyzed.

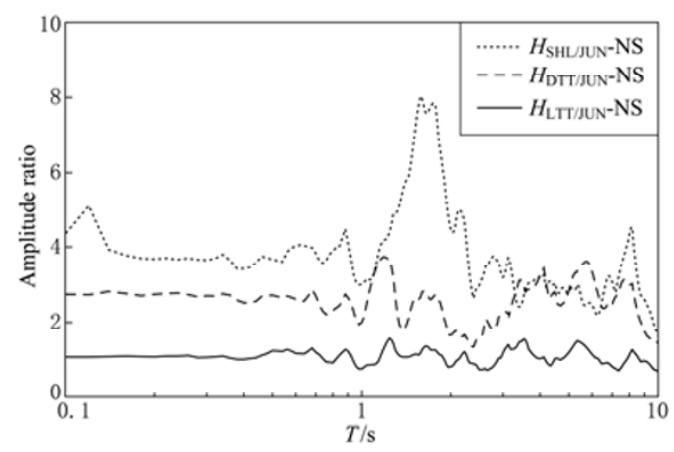

Figure 6 Kagami spectra of the three stations SHL, DTT and LTT with JUN station as reference.

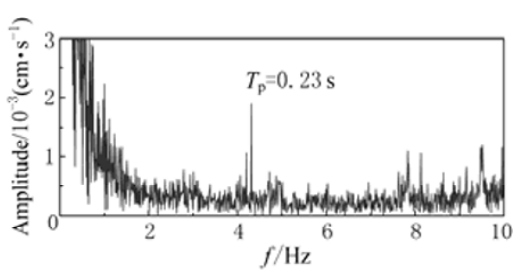

Figure 7 Coda wave and the Fourier spectrum at SHX station.

\section{Conclusions}

On the condition of known site classifications and local site predominant periods, frequency content of ground motions for 12 far-source stations in Shandong province during the Wenchuan earthquake were analyzed by using different methods and then compared, the site-dependence were tested and methods on site analysis were evaluated. Main findings in this paper include the following aspects.

1) Ground motion predominant periods obtained by the Fourier amplitude spectra and earthquake response spectra are much larger than dominant periods of the station site, no order was found on period values for ground motions at different site classes. Frequency content for far-source motions reflects the influence of long-period components, which are dominated by the source and path effects but not the site effect.

2) Ground motion dominant periods yielding from $H / V$ approach mainly emerge aspects of long-period components, and do not accord with station site predominant periods. Kagami spectra of three nearby stations are calculated based on a hard soil site station, results are less than those by Fourier spectra and response 
spectra, but apparently larger than station site periods.

3) Coda wave analysis is performed on SHX station and the motion dominant period approaches to local site period. Hence, for good quality recordings in the far-field region, the CWA can be used to determine site dynamic parameters.

Predominant period derived from data of ground surface shear wave velocity may not be reliable for complicated site such as basin, even for simple soil site the result can only represent effect of local site condition. While for (super-) far-source ground motion, the influence of surface wave is significant, which will contribute much to ground motions rather than the site soil response. Hence, traditional methods (FAS, ERS, $H / V$ and SRRS) cannot be reliably used to characterize local site parameters in the identification of site effects.

Acknowledgements This study is jointly funded by National Natural Science Foundation of China (50808168), Ministry of Science and Technology of Weihai (2008087) and Foundation of Harbin Institute of Technology at Weihai (HIT(Y)200801).

\section{References}

Aki K and Chouet B (1975). Origin of coda waves: Source, attenuation, and scattering effects. J Geophys Res 80: 3 322-3 342.

Beck J L and Hall J F (1986). Factors contributing to the catastrophe in Mexico City during the earthquake of September 19, 1985. Geophys Res Lett 13: 593-596.

Boore D M (2001). Comparisons of ground motions from the 1999 Chi-Chi earthquake with empirical predictions largely based on data from California. Bull Seism Soc Amer 91: 1212-1 217.

Borcherdt R D (1970). Effects of local geology on ground motion near San Francisco Bay. Bull Seism Soc Amer 60(1): 29-61.

Celebi M, Prince J, Dietal C, Onate M and Chavez G (1987). The culprit in Mexico City: Amplification of motions. Earthquake Spectra 3: 315-328.

Chai J, Teng T and Loh C (2004). Determination of first mode ground period and site-dependent design response spectrum for Taiwan High Speed Rail. Soil Dynamics and Earthquake Engineering 24: 527-536.
Chopra A K (2007). Elastic response spectrum: A historical note. Earthq Engng Struct Dyn 36: 3-12.

Fukuwa N (2008). Key parameters governing the dynamic response of long-period structures. Seismology 12: 295-306.

Kagami H, Duke C M, Liang G C and Ohta Y (1982). Observation of 1-to 5-second microtremors and their application to earthquake engineering. Part II. Evaluation of site effect upon seismic wave amplification due to extremely deep soil deposits. Bull Seism Soc Amer 72(3): 987-998.

Koketsu K, Hatayama K, Furumura T, Ikegami Y and Akiyama S (2005). Damaging long-period ground motions from the $2003 M_{\mathrm{W}} 8.3$ Tokachi-oki, Japan, earthquake. Seism Res Lett 76: 67-73.

Lermo J and Chavez-Garcia J (1994). Are microtremors useful in site response evaluation? Bull Seism Soc Amer 84(5): 1350-1 364.

Li C F and Zhang Y (2006). Urgency of the study of long-period ground motion. Seismological and Geomagnetic Observation and Research 27(3): 1-8 (in Chinese with English abstract).

Li C F, Zhang Y, Zhao J B and Tang H (2006). Long-period ground motion characteristic of the 1999 Jiji, Taiwan, main-shock and aftershocks. Acta Seismologica Sinica 19(4): 448-460.

Maeda T and Sasatani T (2008). Long-period ground motions from the 2003 Tokachi-oki earthquake. J Seism 12: 243-253.

Nakamura Y (2000). Clear identification of fundamental idea of Nakamura's technique and its applications. In: Proceeding of the 12th World Conference on Earthquake Engineering. Jan 30-Feb 4, 2000, Auckland, New Zealand, paper No.2656.

Ruiz S and Saragoni G R (2009). Free vibration of soils during large earthquakes. Soil Dynamics and Earthquake Engineering 29: 1-16.

Wang S Y, Yu Y X and Hu Y X (1998). Study of characteristics of long-period ground motion response spectra by using broad-band records of the Chinese Digital Seismograph Network. Acta Seismologica Sinica 11(5): 557-564.

Xie L L, Zhou Y N, Hu C X and Yu H Y (1990). Response spectral characteristics of long-period. Earthquake Engineering and Engineering Vibration 10(1): 1-20 (in Chinese with English abstract).

Xu Y, Zhao J Q, Li X J, Ma X F and Zhao X J (2009). Study on effect of thick sedimentary layers on long-period ground motion from far-field strong motion records of Wenchuan earthquake. Technology for Earthquake Disaster Prevention 3(4): 345-351 (in Chinese with English abstract).

Yu H Y, Wang D, Yang Y Q, Xie Q C, Jiang W X and Zhou B F (2009). The preliminary analysis of strong ground motion records from the $M_{\mathrm{S}} 8.0$ Wenchuan earthquake. Earthquake Engineering and Engineering Vibration 29(1): 1-13 (in Chinese with English abstract).

Yu Y X (2004). Review of long-period ground motion study. Recent Developments in World Seismology (7): 1-5 (in Chinese with English abstract).

Yu Y X and Hu Y X (2001). A combine method to establish attenuation relation of long-period response spectrum. In: Spencer Jr. B F and Hu Y X eds. Earthquake Engineering Frontiers in the New Millennium. A. A. Balkema Publishers, Lisse, 177-182. 